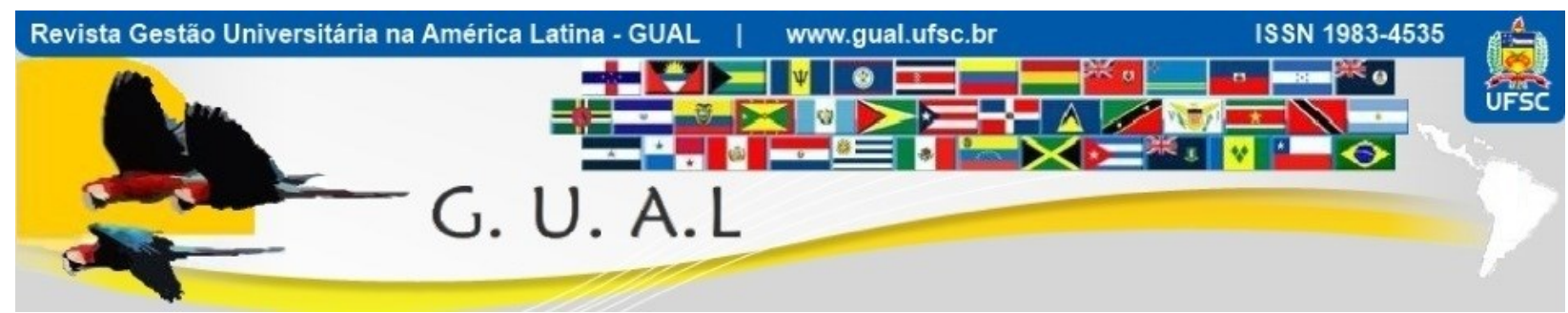

DOI: http://dx.doi.org/10.5007/1983-4535.2014v7n1p1

\title{
TRABALHO E ESTRESSE: IDENTIFICAÇÃO DO ESTRESSE E DOS ESTRESSORES OCUPACIONAIS EM TRABALHADORES DE UMA UNIDADE ADMINISTRATIVA DE UMA INSTITUIÇÃO PÚBLICA DE ENSINO SUPERIOR (IES)
}

\author{
LABOUR AND STRESS: THE IDENTIFICATION OF STRESS AND \\ OCCUPATIONAL STRESSORS IN WORKERS ON AN ADMINISTRATIVE UNIT \\ OF A PUBLIC INSTITUTION OF HIGHER EDUCATION
}

Edward Goulart Junior, Doutor Universidade Estadual Paulista - UNESP $\underline{\text { edward} @ \text { ffc.unesp.br }}$

Hugo Ferrari Cardoso, Doutor Universidade Sagrado Coração - USC hfcardoso@gmail.com

Luiza Calori Domingues, Graduanda Universidade Estadual Paulista - UNESP lu.cdomingues@hotmail.com

Roberta Miguel Green, Graduanda Universidade Estadual Paulista - UNESP green 564@hotmail.com

Thássia Ramos Lima, Graduanda Universidade Estadual Paulista - UNESP thassialima@yahoo.com.br

Recebido em 08/maio/2013

Aprovado em 15/setembro/2013

Sistema de Avaliação: Double Blind Review

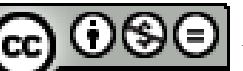

Esta obra está sob uma Licença Creative Commons Atribuição-Uso. 


\title{
RESUMO
}

$\mathrm{O}$ artigo apresenta pesquisa realizada junto a servidores públicos de uma Instituição de Ensino Superior (IES) que teve como objetivo diagnosticar a presença do estresse nessa população, a fase do estresse em que os indivíduos se encontram e a predominância de sintomas, se físicos ou psicológicos. Objetivou também caracterizar o quadro sintomatológico da população que experimenta estresse e os principais estressores do contexto de trabalho onde os participantes atuam. A pesquisa revelou que $46,6 \%$ dos participantes estão experimentando estresse, a sua maioria se encontra em fase de resistência com predominância de sintomas psicológicos. Entre os principais estressores dos contextos de trabalho, destacaram-se o ambiente físico do local de trabalho, infraestrutura do setor de trabalho, processo de avaliação de desempenho profissional adotado pela IES, baixo reconhecimento atribuído ao trabalho realizado e o número reduzido de servidores em determinados setores. Os resultados revelaram a avanço da presença do estresse nessa amostra e a necessidade de ações adequadas de políticas e práticas de gestão de pessoas que visem atuar para minimizar esse fenômeno.

Palavras chave: Estresse. Estressores Ocupacionais. Instituição de Ensino. Psicologia Organizacional.

\begin{abstract}
The article presents survey of public servants of a Higher Education Institution (HEI) that aimed to diagnose the presence of stress in this population, the stress phase in which individuals find themselves and the prevalence of symptoms, whether physical or psychological. This study aimed to characterize the symptomatology of the population experiencing stress and major stressors of the work context where participants act. The survey revealed that $46.6 \%$ of the participants are experiencing stress, mostly found in the resistance phase with predominantly psychological symptoms. Among the major stressors of work contexts, stood the physical environment of the workplace, sector infrastructure work, the process of professional performance evaluation adopted by IES, low recognition given to the work done and the small number of servers in certain sectors. The results revealed the presence of stress advancement of this sample and the need for appropriate policy actions and management practices of people who aim to act to minimize this phenomenon.
\end{abstract}

Keywords: Stress. Occupational Stressors. Educational Institution. Organizational Psychology. 


\section{INTRODUÇÃO}

O mundo do trabalho contemporâneo está cada vez mais complexo e dinâmico. Essa nova realidade coloca o trabalhador e as organizações em estado de alerta. Faz-se necessário reconhecer e compreender com mais precisão o que vem ocorrendo nesse importante espaço de vida das pessoas, ou seja, compreender a relação que se estabelece com a atividade laboral e as possíveis consequências para a saúde do indivíduo, bem como, para os resultados organizacionais. Nessa direção, Goulart Jr e Lipp (2011), apontam que o ser humano possui desejos, pretensões, necessidades no âmbito de vida pessoal e no âmbito laboral, assim como as organizações possuem expectativas de desempenho profissional para alcançarem suas metas e objetivos; essas duas dimensões precisam caminhar harmonicamente.

Ainda de acordo com os autores, as diversas patologias tomadas como ocupacionais prejudicam o indivíduo em diversos contextos de sua vida, sendo que, em muitas vezes, tais patologias podem ser causadas pelo nível de pressão que o colaborador vivencia no seu ambiente de trabalho. De acordo com tal realidade, verifica-se que buscar práticas que objetive prevenir o sofrimento, amenizar danos já ocorridos exercendo uma função educativa, configura-se enquanto importante papel da Psicologia do Trabalho, especialmente no que tange a área da saúde ocupacional. Assim, abrem-se possibilidades de reivindicações por um ambiente de trabalho psicologicamente sadio, reduzindo a impotência perante os eventos que colaboram para o adoecimento do trabalhador. Dentre os problemas que assolam a sociedade em geral, mais especialmente os contextos de trabalho, é possível elencar diversas situações que colocam o trabalhador sob forte tensão, tais como as acentuadas cobranças por produtividade, a sobrecarga de trabalho, ritmos de trabalho acelerados, metas inatingíveis, condições de trabalho inadequadas, medo de perder o emprego, baixo reconhecimento profissional, exposição constante ao risco e periculosidade, problemas de comunicação e de relacionamento interpessoal, competição exagerada dentro do trabalho, entre outras. Essas e outras situações presentes nos espaços cotidianos de trabalho são fatores em potencial que influenciam o desenvolvimento dos transtornos mentais e do comportamento nos profissionais que as vivenciam.

De acordo com Goulart Jr e Lipp (2011), o estresse configura-se atualmente enquanto um fenômeno muito presente em todas as sociedades, atingindo os indivíduos independentes de sua condição econômica e social. Esse fenômeno "abre portas" para doenças, tanto de 
caráter psicológico como físico, trazendo prejuízos acentuados para toda a comunidade. Nas organizações de trabalho, a presença do estresse entre os trabalhadores pode influenciar nos altos índices de absenteísmo, acidentes de trabalho, licença saúde, diminuição da qualidade de vida no trabalho, aumento de conflitos interpessoais, etc; todas essas condições podem favorecer acentuados prejuízos, tanto para os trabalhadores como para as próprias organizações.

\section{COMPREENDENDO O ESTRESSE: BREVES CONSIDERAÇÕES}

De acordo com Lipp (2003), o estresse é definido como um estado de desequilíbrio do organismo. Sua origem está vinculada à necessidade de constante adaptação às mudanças bruscas e rápidas que ocorrem no ambiente, o que demandam mobilização de energia física, mental e social; o estresse se estabelece quando há incongruências entre a capacidade do indivíduo em acompanhar e adaptar-se às transformações, gerando um desequilíbrio no organismo. Embora não exista evidência científica de que as pessoas na sociedade atual sofram mais com a presença do estresse do que em outras épocas, temos que considerar que, na sociedade atual, vem ocorrendo mudanças acentuadas e em uma velocidade também acentuada, obrigando as pessoas a despenderem esforços no sentido de um constante movimento de adaptação as novas situações que se apresentam, fato esse que, provavelmente, acentue a presença do estresse em tempos atuais.

O estresse pode ter efeitos positivos e negativos, podendo levar ou não a um desgaste geral do organismo, dependendo de sua intensidade, habilidade da pessoa para administrá-lo e vulnerabilidade, ou seja, algumas pessoas são mais suscetíveis ao estresse; características pessoais (predisposição genética) e ambientais (aprendizagens inadequadas para lidar com determinados eventos, por exemplo), podem explicar essa condição. As respostas mais comuns do estresse, segundo Lipp e Malagris (2001), são: hipertensão, diabete, alergia (sintomas físicos) e cansaço mental, perda de memória, crise de ansiedade (sintomas psicológicos), entre outros.

O processo de estresse, de acordo com o "modelo trifásico de evolução do stress" proposto por Selye (1956), abrange três fases: de alarme (pessoa se defronta com o estressor - curta duração - e o organismo se prepara para "luta ou fuga"); de resistência (estressor é de longa duração e o organismo tenta restabelecer o equilíbrio, perdido na fase de alarme); de exaustão (quando a resistência do indivíduo não é suficiente para lidar com o estressor). Há 
ainda uma quarta fase, identificada por Lipp (2000), mediante estudos e trabalhos clínicos, denominada quase-exaustão que se encontra entre as fases de resistência e exaustão. Nessa fase, o individuo não é mais capaz de resistir, mas ainda não alcançou a exaustão; o organismo oscila entre momentos de tranquilidade e desconforto, podendo surgir algumas doenças.

Nesse mesmo sentido, o que desencadeia o estresse é chamado pelos autores de estressores, os quais se caracterizam por qualquer situação que gera reações orgânicas ou comportamentais vinculadas a mudanças psicofisiológicas no organismo, exigindo algum tipo de adaptação. Os estressores podem ser acontecimentos positivos ou negativos, como alguma frustração, sobrecarga de trabalho, perdas, dificuldade de se estabelecer relacionamentos interpessoais positivos, entre outros. Existem os estressores externos, vinculados aos contextos do ambiente que afetam o organismo, e os internos, vinculados às características particulares do individuo (pensamentos, emoções, valores, frio, fome, dor etc).

\subsection{TRABALHO, ESTRESSE E ESTRESSORES OCUPACIONAIS}

A presença de estresse minimiza a qualidade de vida das pessoas, afetando o seu comportamento nos diferentes âmbitos de sua vida, sobretudo, no âmbito profissional. De todas as situações que influenciam a vida das pessoas, o trabalho tem papel de destaque por ser uma atividade da espécie humana estando presente à consciência e a intencionalidade. $\mathrm{O}$ trabalho conceituado por diversos autores converge, de forma quase unânime, para uma dimensão: a relação de transformação entre homem e natureza. Segundo Murta e Tróccoli (2004), o trabalho pode ser visto de forma positiva, pois é uma das fontes de satisfação de muitas das necessidades do ser humano, como a auto-realização, manutenção de relações interpessoais e sobrevivência. Mas também ele pode ser visto de forma negativa, quando este contribui para o desgaste da saúde do trabalhador, gerando adoecimento. Bertani (2006), argumenta que quando não há relação satisfatória com o trabalho, a vulnerabilidade do sujeito à doenças aumenta, assim como suas dificuldades em enfrentar seus problemas.

A relação satisfatória com a atividade do trabalho é fundamental e quando ele é dotado de sentido para quem o realiza, torna-se fonte de motivação e satisfação das necessidades, possibilitando o desenvolvimento pessoal. Entretanto, quando este sentido se perde, a realização desta atividade transforma-se em sofrimento psíquico, exercício alienante, impactando na saúde física e metal do trabalhador. Além de interferir na vida diária dos 
trabalhadores no sentido de alteração dos níveis de satisfação, o estresse ocupacional tem sido estudado, segundo Ribas (2009), por alterar a produtividade e saúde dos trabalhadores, ocasionando dificuldades de atenção e concentração, confusão mental, perda temporária de memória, irritabilidade, fadiga, mal-estar generalizado e acidentes de trabalho. Canova e Porto (2010), argumenta que grande parte da literatura específica descreve que o estresse ocupacional seja resultante de um complexo conjunto de fenômenos e não consequência de apenas um fator externo que age sobre o trabalhador. Para os autores o estresse ocupacional pode ser entendido como reação tensional experimentada pelo trabalhador diante de estímulos estressores que surgem no contexto de trabalho e são percebidos como ameaças à sua integridade.

Ainda para os autores, as conceituações sobre estresse ocupacional parecem convergir no sentido de ajuste, quer na relação indivíduo-ambiente de trabalho, quer na demandarecursos, sendo o estresse o resultado de um estado de desequilíbrio dessas questões. Segundo Goulart Jr. (2005), muitos estudos remetem à relação entre estresse e qualidade de vida, uma vez que as relações e experiências geradas no contexto do trabalho podem ser intensa fonte de estressores para os indivíduos, comprometendo assim sua qualidade de vida e bem-estar. Para o autor o estresse ocupacional é experienciado mediante a incapacidade de adaptação do trabalhador, envolvendo assim o desequilíbrio entre exigências e capacidades, sendo descrito enquanto um estado emocional desagradável, pela tensão frustração, ansiedade, exaustão emocional em função de aspectos do trabalho, aspectos esses compreendidos como ameaçadores. Seu agravamento ocorre quando o indivíduo tem dificuldades de se adaptar a situações em que este percebe suas responsabilidades e há pouca possibilidade de autonomia e controle.

Paschoal e Tamayo (2004) define o estresse ocupacional como sendo um processo em que o indivíduo percebe demandas de trabalho como estressores, os quais ao exercer sua habilidade de enfrentamento, provocam no sujeito reações negativas. Os estressores ocupacionais então seriam as ameaças desencadeadoras da reação de estresse do indivíduo no seu ambiente de trabalho. Ainda de acordo com os autores, as percepções dos indivíduos são mediadoras do impacto do ambiente de trabalho sobre eles. Sendo assim, segue-se o raciocínio de que para algo ser um estressor ocupacional, ele necessariamente deve ser percebido como tal pelo trabalhador. Entretanto, os estressores são percebidos e interpretados pelos trabalhadores de formas distintas, o que implica a necessidade de considerar as 
características de cada pessoa, bem como sua capacidade de interação com estas fontes de estresse presentes no ambiente ao qual estão expostas. Um evento estressor pode ser também considerado estressor em um dado momento, mas não em outro.

Também para Fiorelli (2001), as causas do estresse no ambiente de trabalho podem ser de diversas naturezas e devem ser pesquisadas em quatro áreas que se inter-relacionam: (a) fatores relacionados às tarefas; (b) fatores relacionados às normas da organização; (c) fatores relacionados ao processo de trabalho e (d) fatores relacionados às relações interpessoais. Os fatores relacionados às tarefas dizem respeito à necessidade do trabalhador estar atualizado, e, quando essa atualização não ocorre, a carga psíquica do trabalhador é afetada e, conseqüentemente, sua motivação é reduzida. Os fatores relacionados às normas da organização estão ligados ao grau de sintonia entre as exigências da organização e as competências do trabalhador, bem como suas características de personalidade, e, quando essa sintonia é baixa, o equilíbrio emocional do trabalhador pode ser afetado. Quanto aos fatores relacionados ao processo de trabalho, é dever da organização disponibilizar todas as informações necessárias para que o trabalhador possa executar suas tarefas de maneira satisfatória e a falta de informações precisas pode colaborar para a presença do estresse. Para finalizar, os fatores relacionados às relações interpessoais dizem respeito aos conflitos que podem existir no ambiente de trabalho, devido à falta de treinamentos, de informações, fatores inerentes às pessoas ou até mesmo despreparo dos líderes.

Aguiar e Couto, apud Tamayo, Lima e Silva (2004), relacionam eventos estressores e trabalho em termos da sobrecarga do trabalho (tempo insuficiente para realização das tarefas, excesso de responsabilidade, carga de sono reduzida, etc), da falta de estímulo, apoio ou suporte socioafetivo (carência de perspectivas, solidão, tédio, pouco investimento da capacidade de trabalho) e dos constrangimentos organizacionais (problemas de ergonomia, acréscimo de novas tecnologias e mudanças constantes na organização).

Zanelli (2010) argumenta que dentre os agentes estressantes no contexto de trabalho, destacam-se: as demandas acima das condições efetivas de produção ou prestação de serviços com qualidade; pouco reconhecimento profissional; reduzida participação dos trabalhadores nas decisões da organização; longas jornadas de trabalho; dificuldades de promoção; pressão de tempo, excesso de burocracia, entre outros.

Os estressores ocupacionais presentes nos contextos de trabalho afetam diretamente a saúde e bem estar do trabalhador e precisam se reconhecidos e minimizados. Influenciam 
também na satisfação e comprometimento no trabalho, impactando na qualidade de vida do trabalhador. Zanelli (2010) corrobora com essa afirmação quando argumenta que as condições de trabalho têm evidentes implicações na saúde e na qualidade de vida humana.

Segundo Bertani (2006), fala-se muito em qualidade de vida, mas com esse mundo de consecutivos avanços e frenética necessidade de acompanhá-los, não há tempo para viver com qualidade. Ressalta-se então a grande necessidade das políticas e práticas de gestão de pessoas atuarem no sentido de tentar proporcionar um melhor bem estar para o trabalhador, para este executar seu trabalho de modo eficiente, mas com motivação e livre do estresse.

Para Zanelli (2010), a qualidade de vida no ambiente de trabalho envolve aspectos como o significado do trabalho para seu executor, as condições de trabalho, a segurança e os riscos envolvidos, abertura para a criatividade e inovação, as consequências da participação efetiva nos processos de decisão, a percepção que se tem da remuneração e recompensas, possibilidade de desenvolvimento profissional e pessoal, o tratamento que é recebido, a sinceridade nas relações interpessoais, etc. $\mathrm{O}$ autor também entende que as dificuldades na vida familiar acabam interferindo no desempenho profissional, completando-se então um ciclo vicioso, pois há novamente o aumento do nível de tensão e desgaste emocional do trabalhador, tensão esta que, juntamente com os estressores ocupacionais podem desencadear um alto nível de estresse que interferirá na vida pessoal e profissional do trabalhador.

Essas breves explanações, considerando especialmente o estresse ocupacional, sinalizam para a necessidade de as organizações atuarem no sentido de diagnosticar e intervir em condições disfuncionais de trabalho. Condições essas que, de certa forma, influenciam na saúde e bem estar do trabalhador e que devem receber a devida atenção. Essa preocupação vai além da busca de uma maior competitividade e qualidade nas relações pessoais e organizacionais; essa preocupação vem demonstrar o zelo que a organização têm com as condições humanas das relações de trabalho, assumindo uma posição importante de responsabilidade social perante a comunidade que, de uma forma ou de outra, a mantém. Nesse sentido, o presente estudo tem por objetivo investigar a presença de estresse, fase e predominância de sintomas do mesmo, além de analisar os estressores ocupacionais em uma amostra de servidores públicos de uma IES. 


\section{MÉTODO}

\subsection{PARTICIPANTES}

Fizeram parte da amostra da pesquisa 103 servidores da Administração Geral (AG) de uma IES pública. Os participantes do estudo eram provenientes de diversos setores da AG, sendo esses, Biblioteca, Administração Sessão Técnica de Saúde, Centro de Convivência Infantil, Oficina e Marcenaria, Direção e Supervisão, Vigilância, Conversação e Manutenção, Atividades Auxiliares e Zeladoria. No que tange à idade dos participantes, a maior frequência (40,8\%) foi de colaboradores com faixa etária entre 40-49 anos. A maior parte dos servidores participantes é casada $(55,3 \%)$ e possuíam de um a dois filhos $(54,4 \%)$.

Em relação ao tempo de atuação na função atual, o tempo de atuação na Instituição em questão e o período de trabalho dos participantes, de um total de 103 servidores, as maiores frequências foram de profissionais que trabalhavam há mais de 20 anos na sua função atual (34\%) e há mais de 20 anos na Instituição (39,8\%). Em relação ao período de trabalho, a maior parte da amostra trabalhava no período integral $(89,3 \%)$.

\subsection{INSTRUMENTOS}

\subsubsection{Inventário de Sintomas de Estresse para Adultos de Lipp - ISSL (LIPP, 2000)}

O ISSL tem por finalidade identificar a presença, a fase do estresse em que a pessoa se encontra, bem como a predominância de sintomas, se físicos ou psicológicos. O ISSL também revela o quadro sintomatológico apresentado pelos indivíduos. Atualmente o instrumento é reconhecido pelo Conselho Federal de Psicologia (CFP) enquanto um teste psicológico.

\subsubsection{Questionário de estressores ocupacionais}

Para a investigação dos estressores no contexto laboral, foi elaborado pelos autores um conjunto de 26 itens, pelo qual o servidor indicou, por meio de uma escala do tipo Likert de quatro pontos, o quanto determinada situação lhe causa estresse (tais itens podem ser visualizados na Tabela 2). Além dos itens, o questionário contou com um questionário sociodemográfico em que os participantes informaram à respeito de tempo de atuação na IES, turno de trabalho, sexo, idade, escolaridade e estado. 


\subsection{PROCEDIMENTOS}

Primeiramente, foi realizada uma reunião com todos os supervisores dos setores, para oportunizar informações acerca do objetivo da pesquisa. Nessa apresentação houve breve exposição sobre o que é o estresse, e mais especificamente, o que é o estresse ocupacional, além de como ele pode influenciar nas relações de trabalho e na saúde do trabalhador. Os supervisores ficaram responsáveis por informar e sensibilizar os servidores dos seus respectivos setores e criar uma escala com horários para que eles se dirigissem ao local de aplicação dos instrumentos de coleta de dados da pesquisa, juntamente com a equipe de pesquisadores que coletaram os dados. Para tanto, foi elaborado um Termo de Consentimento Livre e Esclarecido, explicando os objetivos e procedimentos do trabalho de pesquisa e cuidados éticos para a sua realização.

\section{RESULTADOS}

Segundo os dados de classificação do ISSL, no que tange à amostra total, 48 (46,6\%) pessoas apresentaram. Desses, $42(87,5 \%)$ encontravam-se na fase de resistência, cinco $(10,4 \%)$ na fase de quase exaustão e um $(2,1 \%)$ na fase de alerta. A divisão por setores pode ser visualizada na Tabela 1.

Tabela 1 Identificação dos participantes por setor e a presença de estresse.

\begin{tabular}{lcc}
\hline \multicolumn{1}{c}{ Setor } & Participantes & Presença de estresse (n/\%) \\
\hline Biblioteca & 21 & $12 / 57,1 \%$ \\
Administração & 12 & $3 / 25 \%$ \\
Sessão Técnica de Saúde & 2 & $0 \%$ \\
Centro de Convivência Infantil & 12 & $9 / 75 \%$ \\
Oficina e Marcenaria & 7 & $5 / 71,4 \%$ \\
Direção e Supervisão & 7 & $4 / 57,1 \%$ \\
Vigilância & 6 & $1 / 16,7 \%$ \\
Conversação e Manutenção & 12 & $3 / 25 \%$ \\
Atividades Auxiliares & 14 & $5 / 35,7 \%$ \\
Zeladoria & 8 & $5 / 62,5 \%$ \\
Setor não identificado & 2 & $1 / 50 \%$ \\
\hline TOTAL & $\mathbf{1 0 3}$ & $\mathbf{4 6 , 6 \%}$ \\
\hline
\end{tabular}

No setor na biblioteca, mais da metade dos servidores apresentaram estresse, com 12 servidores $(57,1 \%)$, sendo que desses, $11(91,7 \%)$ estavam na fase de resistência e um $(8,3 \%)$ na fase de quase exaustão. Em relação à predominância dos sintomas, três servidores 
apresentaram maior frequência em sintomas físicos (25\%), enquanto oito tiveram maior frequência em sintomas psicológicos $(66,6 \%)$ e um indivíduo $(8,3 \%)$ não apresentou predominância.

$\mathrm{Na}$ administração do campus, a minoria apresentou estresse (25\%), correspondente a três funcionários de um total de 12. Em relação às fases do estresse, um deles está na fase de alerta $(33,3 \%)$ e dois na fase de resistência $(66,7 \%)$, sendo que todos possuem prevalência de sintomas psicológicos. No Centro de Convivência Infantil, nove pessoas das 12 apresentaram estresse, o que corresponde a $75 \%$ da amostra. Todos os servidores que apresentaram estresse desse setor estão na fase de resistência e se dividem em predominância de sintomas físicos $(33,3 \%)$ e psicológicos $(66,7 \%)$.

Na Sessão Oficina e Marcenaria, cinco servidores apresentaram estresse (71,4\%), dois deles estão na fase de resistência $(40 \%)$ e três na fase de quase exaustão $(60 \%)$. Em acréscimo, todos com predominância de sintomas psicológicos. Na divisão de Direção e Supervisão, dos sete servidores que participaram de pesquisa, quatro $(57,1 \%)$ apresentaram estresse, sendo que todos se encontram na fase de resistência e com predominância de fatores psicológicos. No Setor de Vigilância, somente um servidor apresentou estresse $(16,7 \%)$, estando ele na fase de resistência e com predominância de sintomas físicos.

Na sessão de conversação e manutenção, 12 pessoas participaram da pesquisa, das quais, três $(25 \%)$ apresentaram estresse, estando esses categorizados na fase de resistência, com predominância de sintomas psicológicos. Na sessão de atividades auxiliares, dos 14 sujeitos, a maioria (64,3\%), composta por nove servidores não apresentaram estresse, e cinco apresentaram $(35,7 \%)$, estando todos na fase de resistência com predominância de sintomas psicológicos.

$\mathrm{Na}$ zeladoria, oito servidores participaram, e cinco deles (62,5\%) apresentaram estresse. Desse total de indivíduos estressados, quatro deles (80\%) se encontram na fase de resistência e um na fase de quase exaustão (20\%). Dos funcionários que apresentaram estresse, dois obtiveram predominância de sintomas físicos (40\%) e três deles, predominância de sintomas psicológicos $(60 \%)$. A tabela 2 revela os dados referentes ao questionário de estressores construído com o propósito de levantar indicadores para futuras intervenções. 
Tabela 2 Estressores ocupacionais em servidores da AG do contexto universitário por frequência de respostas

\begin{tabular}{lcccc}
\hline \multicolumn{1}{c}{ Estressores Ocupacionais } & ME & E & PE & NE \\
\hline Infra-estrutura da IES & 7 & 15 & 43 & 36 \\
Infra-estrutura do setor de trabalho & 15 & 17 & 41 & 29 \\
Segurança do trabalho & 8 & 10 & 37 & 44 \\
Remuneração/salário & 12 & 18 & 32 & 36 \\
A carga horário de trabalho & 8 & 9 & 26 & 56 \\
As exigências (pressão) decorrentes do trabalho & 11 & 18 & 47 & 22 \\
Ambiente físico (ruído excessivo, excesso de calor/frio, falta de & 25 & 25 & 22 & 29 \\
iluminação, etc) & & & & \\
Equipamentos/recursos essenciais para o trabalho & 8 & 22 & 37 & 33 \\
Relacionamento com os outros servidores/colaboradores da minha seção & 5 & 8 & 37 & 49 \\
Relacionamento com os outros servidores/colaboradores de outras & 3 & 11 & 37 & 50 \\
seções & & & & \\
Relacionamento com a chefia (superior imediato) & 11 & 6 & 32 & 53 \\
Comportamento dos alunos da IES (desrespeito, ofensas, inadequação, & 10 & 16 & 25 & 51 \\
etc) & & & \\
Comportamento dos docentes da IES (desrespeito, ofensas, inadequação, & 7 & 14 & 35 & 46 \\
etc) & & & \\
Comportamento dos demais usuários da IES (visitantes, cursinho, & 4 & 3 & 19 & 75 \\
supletivo, pacientes do CPA, etc). & & & & \\
Carga de trabalho (volume das atividades) & 8 & 21 & 37 & 36 \\
Período de trabalho & 5 & 10 & 20 & 60 \\
As orientações (ou falta delas) recebidas por parte da chefia imediata & 11 & 20 & 37 & 33 \\
A comunicação entre os colegas de trabalho & 8 & 14 & 38 & 41 \\
A comunicação com a chefia imediata & 6 & 13 & 32 & 47 \\
A Avaliação de Desempenho (ADP) realizada (Acompanhamento do & 14 & 19 & 34 & 35 \\
Desenvolvimento e Reconhecimento) & & & \\
A pouca autonomia que me é dada para desempenhar meu trabalho & 6 & 14 & 33 & 48 \\
O baixo reconhecimento atribuído ao meu trabalho & 20 & 18 & 25 & 38 \\
A falta de ações para a minha capacitação e formação profissional & 13 & 20 & 28 & 38 \\
Número reduzido de servidores no meu setor de trabalho & 19 & 21 & 30 & 32 \\
A falta de interesse e motivação para o trabalho (minha e dos meus & 9 & 25 & 36 & 30 \\
colegas) & & & \\
O desconhecimento dos objetivos do meu setor de trabalho & 9 & 13 & 33 & 46 \\
\hline
\end{tabular}

Nota: (ME: Deixa-me muito estressado(a), irritado(a), nervoso(a)"; E: "Deixa-me estressado(a), irritado(a), nervoso(a)"; PE: "Deixa-me pouco estressado(a), irritado(a), nervoso(a)"; NE: "Não me deixa estressado(a), irritado(a), nervoso(a)".

Dos 26 itens investigados, foram considerados para apresentação de resultados dessa pesquisa, àqueles que apresentaram maiores frequências de respostas ME e E. Nesse sentido, os itens "Infra-estrutura do setor de trabalho", "Ambiente físico (ruído excessivo, excesso de calor/frio, falta de iluminação, etc)", "A Avaliação de Desempenho (ADP) realizada (Acompanhamento do Desenvolvimento e Reconhecimento)", "O baixo reconhecimento atribuído ao meu trabalho" e "Número reduzido de servidores no meu setor de trabalho" 
foram os mais destacados pelos servidores como sendo os mais estressores no ambiente de trabalho.

\subsection{DISCUSSÃO}

A presença do estresse em servidores que, na maioria, se encontram na fase de resistência e de quase exaustão, indica a presença de um nível significativo e acentuado de tensão, o que pode dar oportunidades à ocorrência de doenças devido à redução do sistema imunológico dessas pessoas e suas consequências. Importante ressaltar que, segundo Lipp e Malagris (1995), na fase de resistência, o organismo atua no sentido de buscar se reequilibrar, ocorrendo uma grande utilização de energia, o que pode gerar sensação de desgaste. Quanto maior o esforço que o indivíduo faz para se adaptar e restabelecer o equilíbrio interior, maior é o desgaste do organismo. Quando o organismo consegue harmonizar-se e resistir adequadamente ao estressor, o processo do estresse se interrompe sem sequelas. Essa fase do estresse possibilita às pessoas aprenderem a lidar com as tensões que estão abalando seu equilíbrio interno, a partir de intervenções individuais e coletivas adequadas, o que vai minimizar e/ou eliminar os sintomas presentes.

Embora em menor número, nos servidores que se encontram na fase de quase exaustão, há um indicativo de evolução do estresse em relação àquelas da fase anterior, ou seja, a fase de resistência. Os resultados revelam que esses profissionais já não estão conseguindo resistir às tensões e restabelecer o equilíbrio interior. Para Lipp (2000) ocorre alternância entre momentos em que os indivíduos conseguem resistir às pressões e tensões do cotidiano e se sentem razoavelmente bem, e outros momentos de desconforto, cansaço e ansiedade. Nessa fase, algumas doenças começam a aparecer, o que demonstra que sua resistência já não está tão eficaz. Nessa mesma direção, de acordo com Goulart Jr. (2005), a diminuição da motivação para o trabalho e da satisfação em exercer as atividades relacionadas aos cargos ocupados, podem contribuir não somente para minimizar o desempenho profissional, mas, sobretudo, para o agravamento do quadro do estresse ocupacional.

Em relação aos estressores ocupacionais, tais tiveram maior frequência: infraestrutura do setor de trabalho, ambiente físico, processo de avaliação de desempenho instituído na IES, baixo reconhecimento atribuido ao trabalho e o número reduzido de servidores/colaboradores no setor de trabalho. Os resultados obtidos relativos aos estressores 
no contexto organizacional, elencados pelos servidores da IES, permitem a emissão de algumas considerações.

No que diz respeito ao ambiente físico e à infraestrutura do setor de trabalho, constata-se que alguns setores de trabalho oferecem instalações adequadas, enquanto outros deixam a desejar. Alguns setores são pequenos para comportarem a totalidade dos servidores e muitas vezes são mal arejados e iluminados, barulhentos, possuem mobiliário inadequado, condições precárias e carência de equipamentos. Além disso, podem existir problemas relacionados à limpeza e higiene em dependências da instituição, todas essas variáveis podem interferir de maneira negativa na atuação do trabalhador. Deve-se considerar que o ambiente físico do trabalho é fator relevante na saúde e bem-estar do trabalhador, influenciando seu desempenho nas tarefas profissionais e na motivação e interesse pelo trabalho.

Em relação à avaliação de desempenho profissional aplicada na IES, constata-se que muitas vezes ela é feita de modo equivocado pelos superiores, não alcançando o objetivo proposto, mas sim, atuando simplesmente para que haja a constatação da existência desse instrumento, ou, pior, servindo muitas vezes como instrumento de ameaça e intimidação para os trabalhadores. No que tange o baixo reconhecimento atribuido ao trabalho, tem-se que a falta de reconhecimento de um trabalho tira o valor merecido que este deveria ter e pode desencadear desmotivação, contribuindo muitas vezes para afastamentos ou para a não atribuição de sentido ao trabalho desempenhado.

Em relação ao número reduzido de servidores no setor de trabalho, a quantidade de servidores atuando nos setores vai afetar diretamente no volume de trabalho desses. As horas normais de trabalho podem vir a tornarem-se insuficientes, obrigando o servidor a destinar boa parte de seu tempo "fora do trabalho", para atender a demanda e as exigências profissionais. Essa sobrecarga do trabalho compromete outras atividades cotidianas dessas pessoas, ou seja, o contato com familiares, principalmente os filhos e cônjuges, a possibilidade de lazer, compromissos pessoais, etc., atividades essas de importância ímpar para o equilíbrio emocional e bem-estar dos indivíduos.

Vale ressaltar que alguns estressores podem causar mais ou menos influência na vida de diferentes indivíduos e alguns fatores podem ser apontados como favorecedores do desenvolvimento do estresse. França e Rodrigues (2005) apontam que os estressores podem tanto fazer parte do meio interno quanto do externo, e, assim, determinadas características 
individuais e dos contextos de trabalho, podem contribuir para o nível de intensidade do estressor.

\section{CONCLUSÃO}

O estudo apresentado objetivou identificar a presença do estresse, a fase em que ele encontra-se e a predominância de sintomas, bem como os possíveis estressores ocupacionais junto a servidores de uma unidade administrativa de uma IES. Os resultados obtidos vêm corroborar com outros estudos que apontam para o aumento da presença do estresse nos contextos de trabalho, sinalizando para a necessidade, cada vez mais efetiva, de diagnosticar suas causas e seu impacto nas relações de trabalho e na qualidade de vida dos profissionais. Esse diagnóstico vai favorecer o planejamento de intervenções que venham ao encontro de um ambiente de trabalho mais promotor de saúde e bem estar do trabalhador.

Nesse estudo, observou-se resultados diferenciados conforme os setores de trabalho, o que, provavelmente, possa indicar que algumas atividades realizadas nos diferentes setores, podem caracterizar-se como mais desgastantes do que outras. Essa questão será trabalhada em análises mais pormenorizadas, que serão investigadas com a continuidade desse estudo.

Os resultados do estudo sinalizaram a predominância de sintomas psicológicos $(70,8 \%)$ nas pessoas que experimentam estresse. Esses dados demonstram o avanço significativo dos transtornos mentais e do comportamento nos contextos de trabalho e esse avanço, de certo modo, representa mudanças significativas nos impactos que as relações de trabalho exercem atualmente na saúde dos trabalhadores. Essa questão vai demandar novas formas de "olhar" para a relação homem e trabalho, com intervenções adequadas, sobretudo no âmbito preventivo.

Entende-se que a significativa presença do quadro sintomatológico de ordem psicológica, provavelmente, esteja influenciando negativamente as relações interpessoais que os servidores devem estabelecer entre si e com outras pessoas da comunidade acadêmica, tais como, os alunos, docentes e servidores de outras unidades. Assim como, considerar que o quadro de sintomas apresentados pelos servidores, talvez também possa estar influenciando negativamente na qualidade da comunicação assertiva, no nível de motivação do servidor e no grau de satisfação com o trabalho.

Sabe-se que o trabalho é vital para o ser humano e, torná-lo mais participativo, favorecendo a expressão das potencialidades e talentos, pode resultar positivamente na saúde 
mental e física dos trabalhadores. Assim, o desenvolvimento de programas de redução do estresse poderá promover saúde e qualidade de vida para o contexto organizacional, direcionando também intervenções para programas de desenvolvimento humano e, como consequência, propiciar eficiência e crescimento para as organizações. O tema abordado nesse estudo é relativamente novo no âmbito da psicologia, portanto, uma maior consolidação se efetivará na medida em que teoria e prática passarem se desenvolver de forma conjunta. Evidenciou-se, assim, a necessidade de intervenções voltadas para a realização de trabalhos preventivos que possam amenizar os efeitos do estresse.

O fenômeno da presença do estresse nos ambientes de trabalho mostra-se crescente e o estudo apresentado vem corroborar com a necessidade de as organizações adotarem procedimentos (políticas e práticas) de gestão de pessoas que visem a promoção da saúde de seus trabalhadores para o êxito dos resultados organizacionais. Longe de querer esgotar o assunto, o estudo aqui retratado pode favorecer novos estudos na direção de uma maior compreensão sobre a complexa relação homem e trabalho, sobretudo nos dias atuais, nos quais novas demandas estão constantemente se apresentando e impactando na saúde e bem estar dos trabalhadores.

\section{REFERÊNCIAS}

BERTANI, I. F. Retratos da Saúde: O relatório QUAVISSS. Franca: Legis Summa Ltda, 2006

CANOVA, C. R.; PORTO, J. B. O impacto dos valores organizacionais no estresse ocupacional: um estudo com professores do ensino médio. Revista de Administração Mackenzie, v. 1, n. 5, p. 4-31, 2010.

FIORELLI, J. O. Psicologia para administradores: integrando teoria e prática. 2. ed. São Paulo: Atlas, 2001.

FRANÇA, A. C. L.; RODRIGUES, A. L. Stress e Trabalho: Uma abordagem Psicossomática. São Paulo: Atlas, 2005.

GOULART JR, E. (2005). Stress de professores e estilos de lideranças em escolas públicas. 2005. Campinas. Tese de doutorado não-publicada, Programa de Pós-Graduação em Psicologia, Pontifícia Universidade Católica de Campinas.

GOULART JR, E.; LIPP, M. E. N. Estilo de liderança e estresse: uma pesquisa em escolas estaduais de ensino fundamental. Revista brasileira de política e administração da educação, v. 27, n. 2, p. 153-360, 2011. 
LIPP, M. E. N. Inventário de sintomas de stress para adulto de Lipp-ISSL. São Paulo: Casa do Psicólogo, 2000.

LIPP, M. E. N. Mecanismos neuropsicofisiológicos do stresse: teoria e aplicações clínicas. São Paulo: Casa do Psicólogo, 2003.

LIPP, M. E. N.; MALAGRIS, L. E. N. Manejo do Estresse, In: RANGE B. (org.): Psicoterapia Comportamental e Cognitiva: pesquisa, aplicações e problemas. Campinas, Editorial Psy, 1995.

LIPP, M. E. N.; MALAGRIS, L. E. N. O stress emocional e seu tratamento. In RANGE, B. (Org), Psicoterapias cognitivo-comportamental. Rio de Janeiro: Artmed, 2001.

MURTA, S. G.; TRÓCCOLI, B. T. Avaliação de intervenção em estresse ocupacional. Psicologia: Teoria e Pesquisa, v. 20, n. 1, p. 39-47, 2004.

PASCHOAL, T.; TAMAYO, A. Impacto dos valores laborais e da interferência família: trabalho no estresse ocupacional. Psicologia: Teoria e Pesquisa, v. 21, n. 2, p. 173-180, 2004.

RIBAS, M. C. Vulnerabilidade ao stress no trabalho: Investigação com auxiliares e técnicos de enfermagem. 2009. Trabalho de conclusão de curso (especialização em psicologia da saúde: práticas clínicas e hospitalares). Instituto de Psicologia, Universidade Estadual Júlio de Mesquita Filho, Bauru. (2009)

SELYE, H. Stress e tensão. 2.ed. São Paulo: IBRASA, 1965.

TAMAYO. A.; LIMA, D.; SILVA, A. V. (2004). Clima organizacional e estresse no trabalho. Cultura e saúde nas organizações. Porto Alegre: Artmed, 2004. p. 77-101.

ZANELLI, J. C. Estresse nas organizações de trabalho: compreensão e intervenção baseadas em evidências. Porto Alegre: Artmed, 2010. 